\title{
NUEVAS ESTRATEGIAS DE NEGOCIO Y VALORIZACIÓN DE LOS ARCHIVOS AUDIOVISUALES EN INTERNET
}

Iris López-de-Solís y Carlos Martín-López
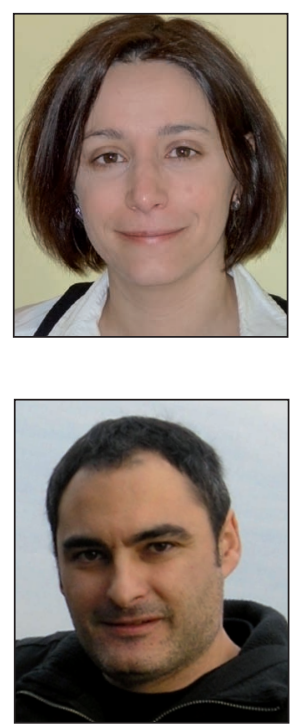

Iris López-de-Solís es licenciada en historia por la Universidad Complutense de Madrid, máster en información y documentación por la Universidad Carlos III de Madrid y DEA en documentación por la Universidad Complutense, donde actualmente lleva a cabo su tesis doctoral. Trabaja como documentalista en los Informativos de TVE en Madrid. Es docente en el Máster de Documentación Audiovisual del IRTVE y la Universidad Carlos III. Sus líneas de investigación se centran en la documentación audiovisual en cine y televisión.

SS II TVE. Torrespaña Alcalde Sáinz de Baranda, 92. 28007 Madrid iris.lopez@rtve.es

Carlos Martín-López es licenciado en documentación y diplomado en biblioteconomía y documentación por la Universidad de Salamanca, máster en documentación audiovisual por la Universidad Carlos III de Madrid y DEA en documentación por la Universidad Complutense. Trabaja como documentalista en laSexta Noticias. Ha trabajado en Antena 3 noticias y en programas de televisión de las productoras Globomedia y Mediapro.

Ciudad de la Imagen. Edificio Mediapro Virgilio, 2, Pozuelo de Alarcón. 28223 Madrid cmartin@snoticias.tv

\section{Resumen}

La digitalización y el desarrollo de las posibilidades que ofrece internet están favoreciendo que los archivos audiovisuales incorporen parte de sus fondos a la Web, con fines comerciales, no lucrativos o educativos. Se describen los diferentes servicios de las páginas web de los archivos según su naturaleza y los usuarios finales, el desarrollo de nuevas estrategias de negocio, la presencia en las redes sociales, la creación de canales de distribución, programas educativos y proyectos de cooperación. Además el acceso abierto a los fondos de muchos archivos en la Web favorece el trabajo de las producciones cinematográficas, que encuentran en ellos una nueva fuente de inspiración.

\section{Palabras clave}

Archivos audiovisuales, Documentación audiovisual, Fuentes de información, Internet, Estrategias de negocio, Programas educativos, Web 2.0, Redes sociales, Digitalización.

\section{Title: New business strategies and valorization of online audiovisual archives}

\begin{abstract}
Digitization and the rapid development of Internet capabilities are encouraging audiovisual archives to add parts of their collections to the web, both for commercial and for nonprofit or education purposes. This article describes the different services offered by online archives, befitting the nature of the archive and of the end users in each case, their development of new business strategies, presence in social networks, creation of distribution channels, educational programs and collaboration projects. Moreover, the open access that the Internet allows also helps film production companies, who find in these archives a new source of inspiration.
\end{abstract}

\section{Keywords}

Audiovisual archives, Audiovisual documentation, Information sources, Internet, Business strategies, Education programs, Web 2.0, Social Networks, Channels of distribution, Digitization.

López-de-Solís, Iris; Martín-López, Carlos. "Nuevas estrategias de negocio y valorización de los archivos audiovisuales en internet". El profesional de la información, 2011, noviembre-diciembre, v. 20, n. 6; pp. 659-666. 


\section{Introducción}

Los archivos audiovisuales se encuentran plenamente inmersos en la era de la digitalización, y están llevando a cabo diversos proyectos para conservar y hacer más accesibles sus fondos. Como han señalado algunos autores (López-deQuintana, 1998; Ubois, 2005), las posibilidades que ofrece internet y el aumento de ancho de banda han propiciado que los archivos audiovisuales no dejen pasar la oportunidad de colocar sus materiales en la Web con diversos fines y estrategias de negocio.

Esto sucede tanto en los archivos públicos e institucionales (por ejemplo, el Institut National de l'Audiovisuel) como en los comerciales (Associated press, ITN source o Getty images). Además de digitalizar, también aprovechan las nuevas oportunidades de la web 2.0, creando perfiles en redes sociales (Crymble, 2010) y fomentando la participación del usuario.

El objetivo de este artículo es presentar los servicios que los archivos audiovisuales ofrecen en internet para valorizar sus fondos de forma que sean consultados por diferentes tipos de usuarios: no especializados (estudiantes, investigadores, público en general) y profesionales relacionados con la producción de contenidos para medios audiovisuales.

Para ello se ha realizado un análisis de contenido de las páginas web de diversos archivos audiovisuales comerciales, públicos e institucionales que tienen disponible parte de su fondo en la Red, así como de proyectos colaborativos entre ellos.

\section{Servicios comerciales}

En la realización de programas televisivos, documentales, películas, series y anuncios se necesitan a menudo documentos audiovisuales. Las búsquedas de este material las llevan a cabo generalmente documentalistas audiovisuales, denominados en el mundo anglosajón researchers (Emm, 2002).

Hasta hace pocos años era necesario trasladarse a las instalaciones de los archivos para realizar las búsquedas de material, buscar en sus catálogos y visionar los documentos en el mismo lugar. El primer cambio en este modo de trabajar surgió con la aparición de las cintas VHS: los archivos recibían las peticiones, realizaban las búsquedas y enviaban las copias o repicados del original en cinta (con el tiempo se pasó a enviar copias en DVD). El cliente recibía por mensajería las imágenes, hacía un visionado, seleccionaba las que necesitaba y realizaba una segunda petición al archivo con las imágenes seleccionadas. Una vez realizada la compra, recibía el material en formato profesional, lo que suponía un ahorro notable de coste y tiempo (Nachreiner, 2009).

La evolución no ha cesado y en la actualidad numerosos archivos au- diovisuales, tanto comerciales como institucionales o no lucrativos, han optado por aprovechar las posibilidades de internet y han desarrollado estrategias de negocio o difusión en la Red. Permiten el acceso en línea a su catálogo y sus bases de datos, así como la integración de vídeos para la previsualización de las imágenes. También incluyen nuevas herramientas que facilitan el trabajo de los usuarios de forma más atractiva y eficaz, como:

- Streamming, visionado del material en baja calidad con marcas de agua (watermarking).

- Keyframes o storyboards del material seleccionado, lo que ayuda a valorar rápidamente si un clip puede o no interesar sin necesidad de ser visionado. Algunos como L'Institut National de l'Audiovisuel ofrecen la posibilidad de seleccionar el intervalo de visionado de los frames. http://www.inamediapro.com

- Búsqueda de clips similares, mediante la selección y combinación de los descriptores incluidos en el clip. Este sistema es utilizado por la página del British Pathé, uno de los archivos pioneros en digitalizar sus fondos (De-la-CuadraColmenares, 2005).

http://www.britishpathe.com

- Descarga de copias en baja calidad. Esta opción es de gran utilidad en la fase de preproducción y producción de una obra audiovisual que requiera imágenes de archivo. EI montador incluye el material seleccionado en las distintas secuencias y el director valora con antelación las alternativas. La descarga normalmente sólo la pueden realizar usuarios registrados para evitar un uso inadecuado de las imágenes. En otros casos, este control se realiza para que personal del propio archivo se ponga en contacto con el usuario, bien para ofrecerles su ayuda, para informar de la existencia de imágenes similares no digitalizadas o para proporcionar y negociar una tarifa de los clips utilizados si finalmente se decide comprar.

- Creación de espacios de trabajo (workspaces), con carpetas o bines (cestos), que permiten agrupar los clips por

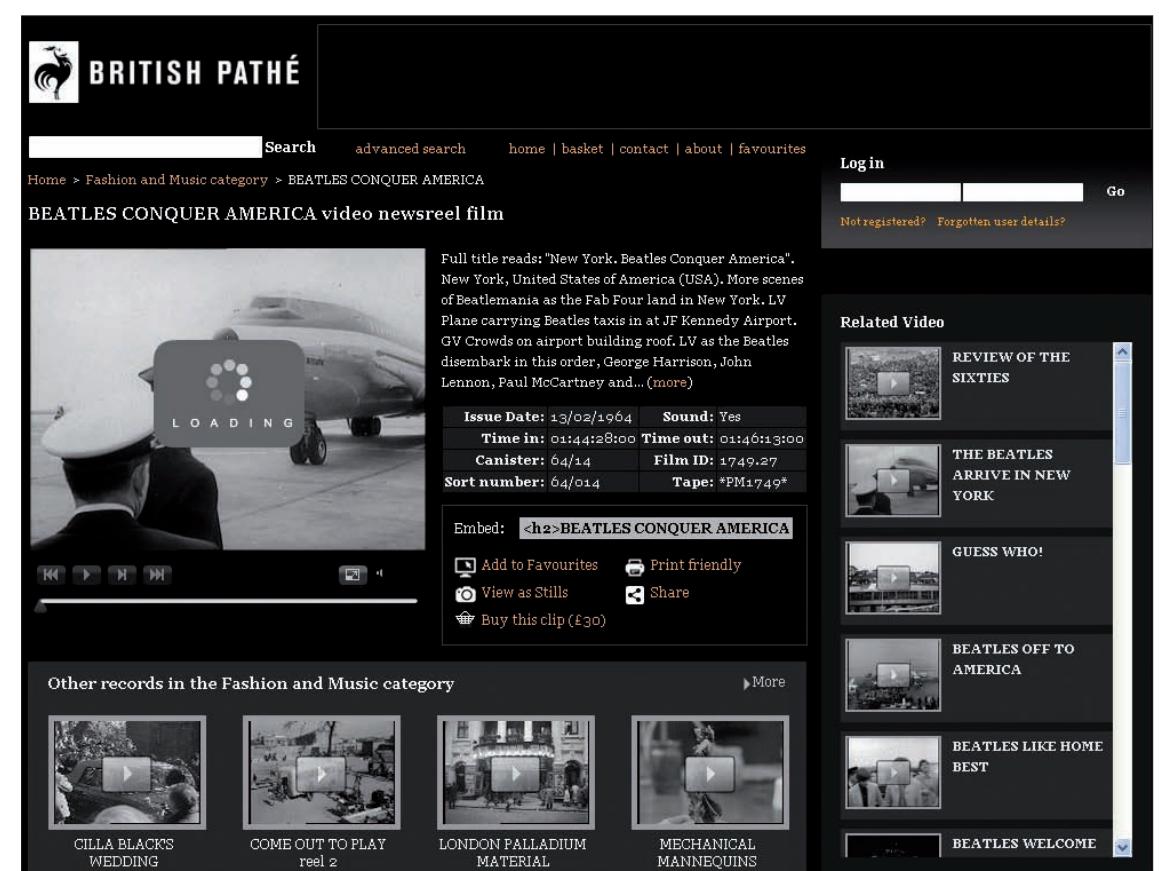

Archivo audiovisual de British Pathé 


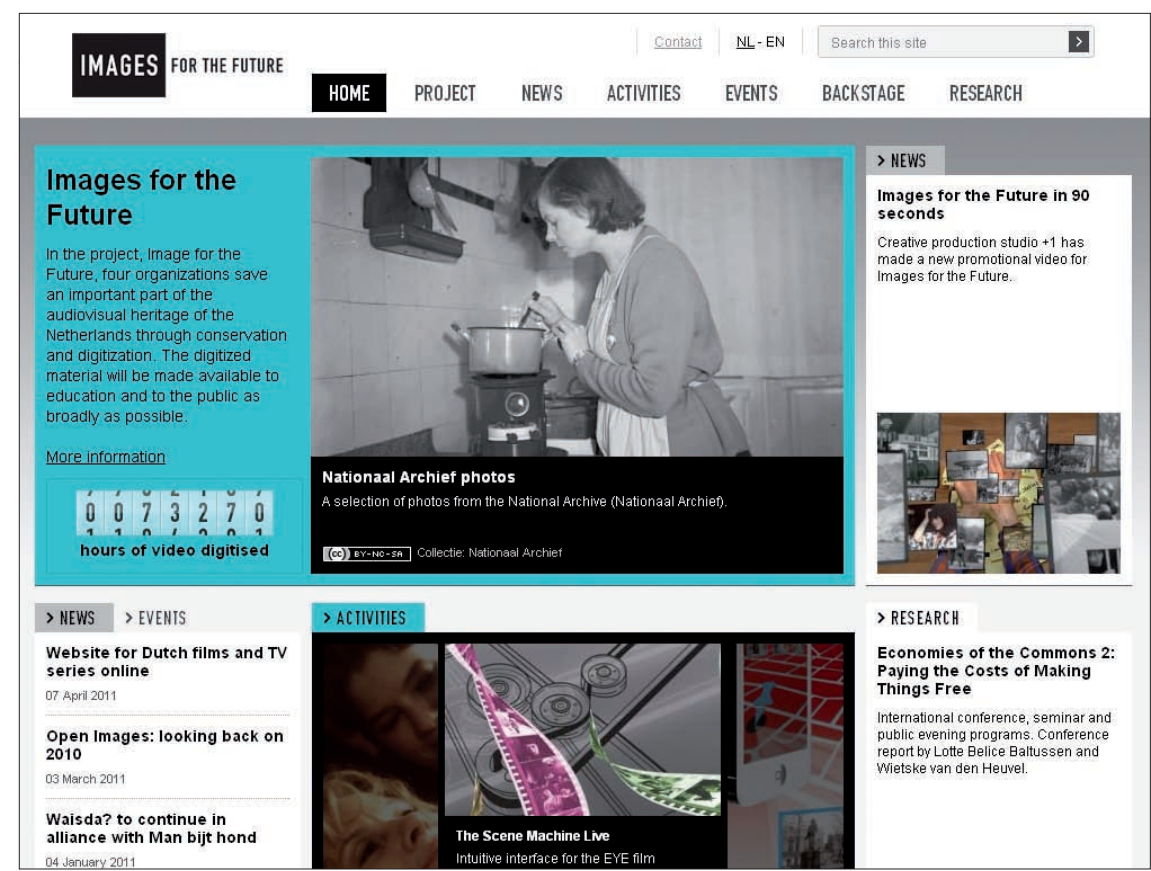

Proyecto Images for the future

temas o por proyectos. En algunos casos, como en ITN source o el INA, los espacios pueden ser compartidos o enviados a otros usuarios, lo que facilita que los directores o guionistas de obras audiovisuales accedan más fácilmente a las imágenes seleccionadas.

http://www.itnsource.com

http://inamediapro.com

- Acceso directo a las tarifas de los clips. Archivos como ITN Source, BBC Motion Gallery o Getty Images, ofrecen este servicio, que sólo está disponible en los clips en los que no hay conflictos de derechos ni se necesita la autorización de otros archivos propietarios de las imágenes.

http://bbcmotiongallery.com

http:://www.gettyimages.es

- Envío de correos electrónicos con boletines de noticias (newsletters) a los usuarios registrados para mantenerlos informados de las novedades sobre fondos y servicios.

- Sindicación a feeds que permite a los suscriptores estar informados de cualquier novedad publicada en la página o blog del archivo.

La existencia de fondos de archivos audiovisuales en la Web facilita enormemente la búsqueda en varios en poco tiempo

Por otra parte, para ser más rentables y competitivos, han desarrollado iniciativas de colaboración. Una de ellas es la representación de otros archivos (partners) para aumentar su visibilidad dentro del mercado, bien por ser menos conocidos o por ser de otro continente o país. Algunos ejemplos son ITN Source que representa entre otros a Fox Movietone, Channel 9 Australia y HUCT, o AP Archive, con contenidos de $A B C$ Video Source, Australia Broadcasting Corporation o CCTV China.
Otra iniciativa es la participación en páginas en las que el usuario puede buscar en fondos de varios de ellos simultáneamente, como Stockfootage o Footage.net. Estos sistemas ofrecen además la opción de zap request, a través de la que se puede enviar un correo a todos los archivos participantes. http://stockfootageonline.com http://www.footage.net

\section{Marketing, editorialización y web 2.0}

La existencia de fondos de archivos audiovisuales en la Web facilita enormemente la búsqueda en varios en poco tiempo, por lo que el usuario tiene ahora mayores posibilidades de elección y comparación. Esto ha propiciado la creación de diversos servicios con el objetivo de atraer al cliente y diferenciarse de los demás.

La realización de dossieres biográficos y temáticos relacionados con la actualidad informativa y efemérides es uno de ellos. Un ejemplo es el dossier de ITN Source relacionado con el compromiso oficial del príncipe Guillermo de Inglaterra en el que se recogen una selección de imágenes de su vida, de Carlos de Inglaterra y de la princesa Diana, así como de otros compromisos de la casa real inglesa y de bodas de herederos de realezas europeas. Otro ejemplo es el dossier que elaboró BBC Motion Gallery con motivo del 30 aniversario de la muerte de John Lennon, que contenía 61 clips sobre su asesinato y su trayectoria musical con los Beatles. http://www.itnsource.com/special/royalengagement http://www.bbcmotiongallery.com/gallery/bin/15142864. do?binName=John\%20Lennon\%20/\%20Beatles07052066/

Los archivos están optando también por crear sus propios canales de distribución en plataformas como Youtube. No sólo comparten clips de sus fondos, sino que incluso realizan montajes atractivos con material de diversos clips, como el de British Pathé con una selección de los mejores momentos de la historia de Wimbledon. Otros ejemplos de esta tendencia son el canal de Alaska Film Archives o de algunas bibliotecas presidenciales de EEUU, como las de Nixon y Kennedy.

http://www.youtube.com/user/britishpathe http://www.youtube.com/user/alaskafilmarchives

En las redes sociales han encontrado asimismo una oportunidad de publicitarse gratuitamente e interactuar con los usuarios (Crymble, 2010). Por ello cada vez están más presentes en alguna red social, principalmente en Twitter(ITN Source Nederlands Instituut voor Beeld en Geluid) y Facebook (British Pathé, Steven Spielberg Jewish Film Archive o BBC Motion Gallery).

A través de sus perfiles anuncian sus novedades o la adquisición de nuevos fondos, así como la inclusión continua de clips para que puedan ser visionados por sus seguidores. Opciones como los retuits en Twitter o las publicaciones 
compartidas en Facebook posibilitan el incremento de usuarios y seguidores.

Algunos han optado por crear blogs para mantener informados a los usuarios de las novedades o para explicarles el funcionamiento de ciertos elementos de la página, como el blog de Internet Archive. Otros, como el blog de British Pathé han dado un paso más y animan a los usuarios a que participen y escriban sus propios posts.

http://blog.archive.org

http://britishpathe.wordpress.com

Para coordinar su presencia en la web social algunos medios digitales han creado la figura del gestor de medios sociales, un nuevo perfil que podría ser asumido por documentalistas (Rubio-Lacoba, 2010). En el sector de los archivos audiovisuales parece también claro que esta labor podría ser realizada por gestores de información, capaces de aumentar la visibilidad de los fondos documentales.

Una tendencia nueva de los archivos audiovisuales en internet es el desarrollo de servicios 2.0 en los que el usuario participa e interactúa con el sitio web

\section{Crowdsourcing: el usuario enriquece el archivo}

Una tendencia nueva de los archivos audiovisuales en internet es el desarrollo de servicios 2.0 en los que el usuario participa e interactúa con el sitio web. Ya no se trata de crear simplemente páginas estáticas, sino de que los usuarios participen en experiencias online. Algunos casos que se pueden destacar son:

- Identificación de gente anónima.

El archivo de la Télévision Suisse Romande incluye un apartado denominado Inconnu à ce jour, con imágenes de personas anónimas o sin identificar para que el propio usuario realice esta labor.

http://archives.tsr.ch/home

- Identificación de personajes famosos.

Canadian Broadcasting Corporation incluye en su web un servicio donde se pueden visionar imágenes de famosos en su juventud o en sus inicios profesionales para adivinar quiénes son.

http://archives.cbc.ca

- Inclusión de tags por parte del usuario.

El Nederlands Instituut voor Beeld en Geluid creó en 2009 el proyecto Waisda, en el que se invitaba a los usuarios a añadir tags a las imágenes, obteniendo puntos si otra persona incluía las mismas. A través de esta iniciativa se intentó tender un puente entre los términos usados por los profesionales y los utilizados por los usuarios en sus búsquedas (Oomen et al., 2010). La evaluación de esta primera fase del proyecto indica que éstos optan por términos no incluidos en los lenguajes controlados (Gligorov et al., 2011).

http://portal.beeldengeluid.nl

- Comentarios, rankings y envío de clips.

Las posibilidades de comentar los clips visionados, de establecer categorías y rankings de clips más populares, y de envío de clips por correo electrónico, las ofrece la página de acceso público del INA.

http://www.ina.fr

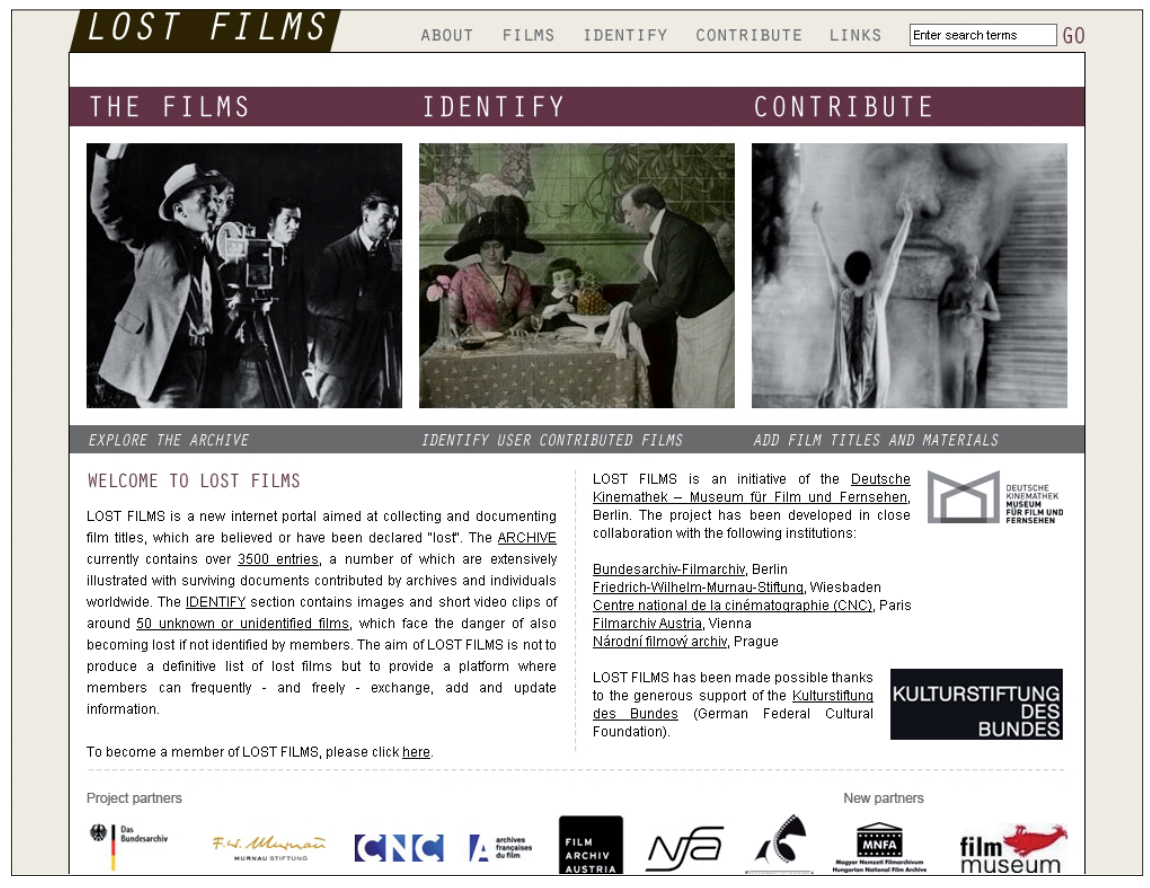

Página web de Lost films 


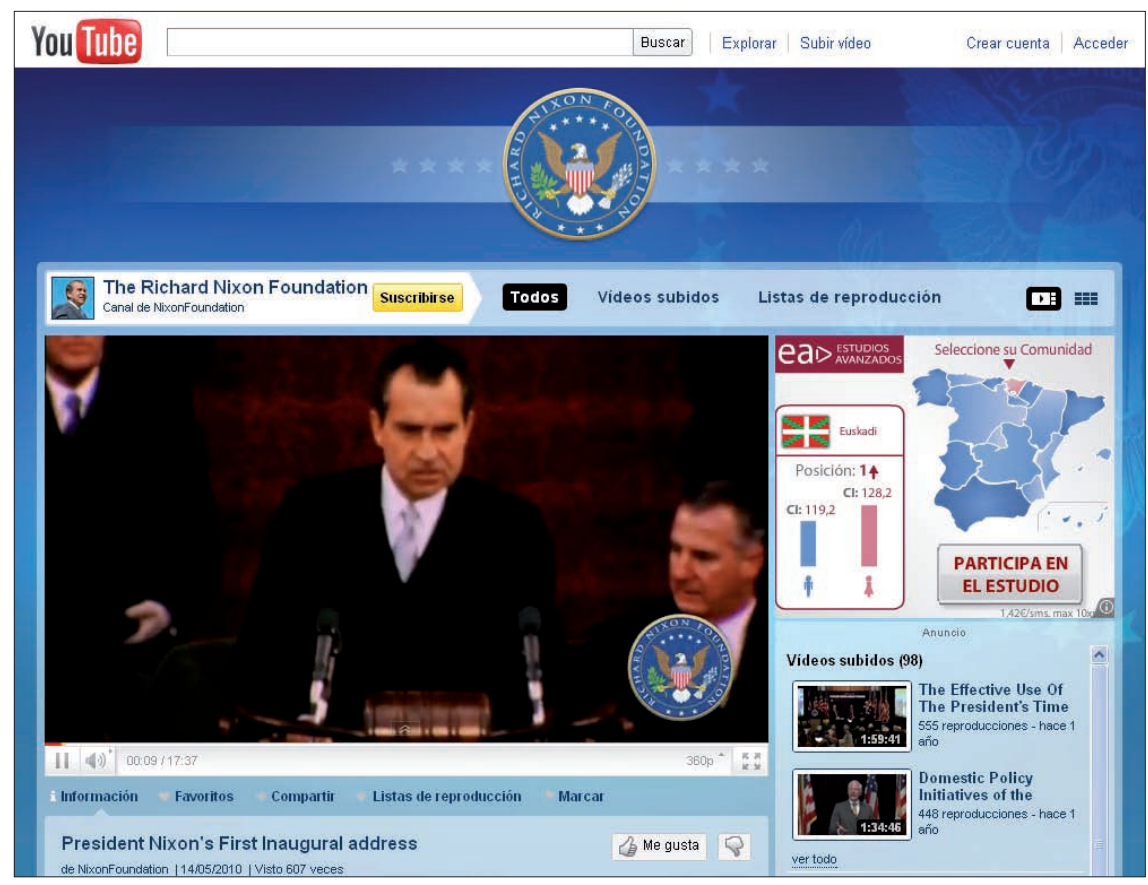

Canal en Youtube de la Biblioteca Presidencial de Richard Nixon

\section{- Compartir clips.}

Algunos archivos cuentan con herramientas para compartir e incluir clips embebidos en una página web a través de botones insertados en el vídeo, que permiten acceder a su código html para incorporarlo a nuevos documentos o compartirlos a través de las redes sociales y correo electrónico. Por ejemplo, el archivo del Servicio Audiovisual de la Comisión Europea.

http://ec.europa.eu/avservices

- Otras iniciativas.

El archivo de la Télévisión Suisse Romande y la Fondation pour la sauvegarde des archives audiovisuelles de la TSR (FONSAT) desarrollaron el proyecto denominado Notrehistoire, una plataforma participativa con material audiovisual procedente de particulares, bibliotecas, museos, empresas y asociaciones. Otras iniciativas interesantes son Treasure Hunt, desarrollada por la $B B C$, donde se animaba a los usuarios a aportar documentos audiovisuales, o el proyecto de la Cinemateca Alemana denominado Moments in time 1989/90, donde se recogen fotografías y películas personales tomadas durante los años de la caída del muro de Berlín y la reunificación alemana. También la Cinemateca Alemana ha participado en Lost films, un portal creado por el Museo del Cine y la Televisión de Berlín, destinado a coleccionar y documentar títulos de films que se consideran o han sido declarados perdidos y donde el usuario puede enriquecer la información de las imágenes a través de sus comentarios.

http://www.notrehistoire.ch

http://www.bbc.co.uk/cult/treasurehunt http://www.wir-waren-so-frei.de/

http://www.lost-films.eu

\section{El interés creciente de la comunidad edu-} cativa por el material audiovisual como apoyo a la docencia encuentra también respuesta en los archivos audiovisuales

\section{Servicios con fines educativos: \\ la contextualización de los fondos}

El interés creciente de la comunidad educativa de usar material audiovisual como apoyo a la docencia encuentra también respuesta en los archivos audiovisuales a través de iniciativas desarrolladas principalmente por parte de archivos públicos.

Este es el caso de los proyectos British Film Institute Screenonline o Australian Screen. También el British Film Institute ha creado la página British Film Institute InView donde la instituciones académicas de Reino Unido pueden acceder a más de 2.000 clips comentados por historiadores.

http://www.screenonline.org.uk http://aso.gov.au http://www.bfi.org.uk/inview

En una línea similar se encuentran diversos proyectos pertenecientes a Images for the Future, cuyo objetivo es hacer accesible el patrimonio audiovisual holandés al público en general y a las instituciones educativas. Se trata de Academia, con material para edu-

Página en Facebook del Steven Spielberg Jewish Film Archive 
cación superior, y Ed-it, para estudiantes de primaria.

http//imagesforthefuture.com/en

http://www.academia.nl

http://www.ed-it.nu

Algunos archivos comerciales se están sumando a estas iniciativas con fines educativos. ITN, conjuntamente con el British Film Institute, participa en el proyecto Newsfilm Online, de material audiovisual para uso educativo en Reino Unido. Otro caso es el de British Pathé, que también ha creado servicios específicos para que los docentes puedan utilizar material digitalizado procedente de sus fondos.

http://newsfilm.bufvc.ac.uk

En todos estos proyectos se realiza una selección de clips según su valor educativo y se establecen categorías temáticas, así como divisiones por periódicos históricos. En algunos casos

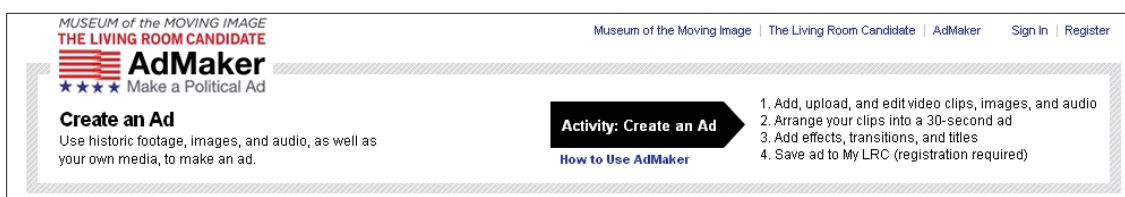
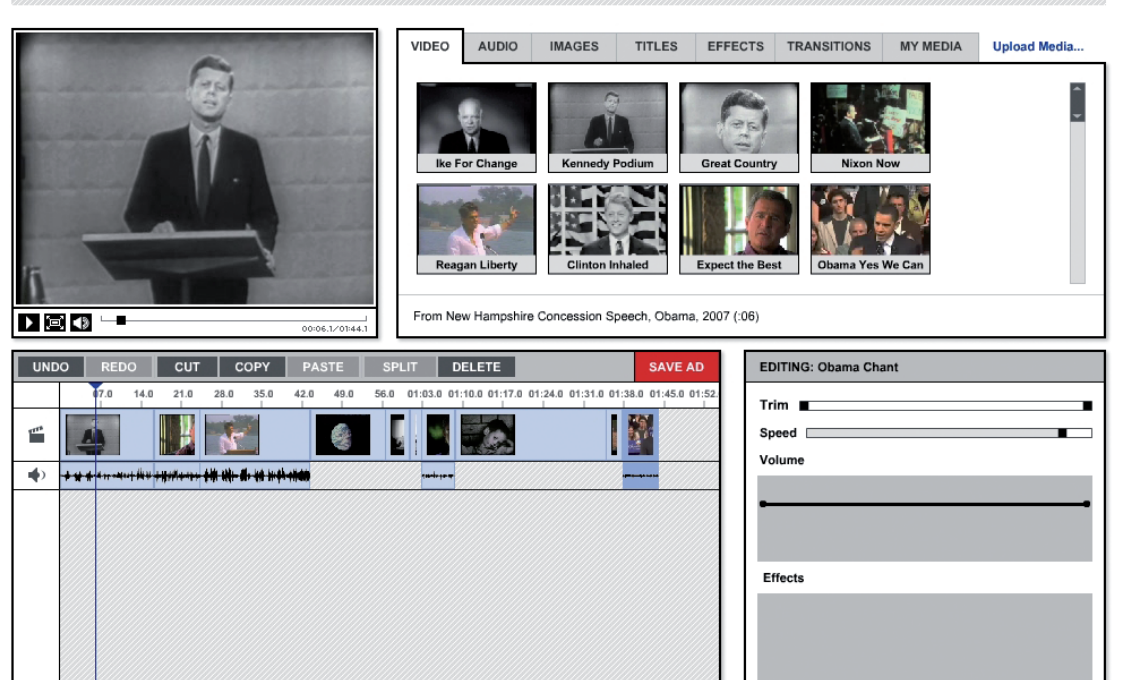

Aplicación AdMaker en The living room candidate

(como en Australian Screen Online), los clips van acompañados por guías elaboradas por expertos para orientar al docente.

Un paso más en los servicios educativos es la posibilidad de que el alumno/usuario pueda editar material de archivo. El British Film Institute Screenonline tiene una aplicación en línea para editar imágenes denominada The cutting room con una selección de material histórico, principalmente noticieros cinematográficos. Similar es The living room candidate, del Museum of Moving images de Estados Unidos, que contiene más de 300 spots de las elecciones presidenciales desde 1952. La aplicación Admaker permite editar algunos de estos materiales, añadiendo música, fotografías e incluso efectos. Otra iniciativa interesante es Filmrestauratie, del Film Museum en Holanda, que convierte al usuario en restaurador de películas.

http://www.screenonline.org.uk/education/thecuttingroom http://www.livingroomcandidate.org

http://filmrestauratie.filmmuseum.nl

A nivel más específico destaca el proyecto Screen search fashion, elaborado por el Royal College of Art y el Screen Archive South East de la University of Brighton, en el que se puede acceder a diferentes clips digitalizados referentes a la moda entre 1920 y 1930.

http://www.brighton.ac.uk/screenarchive/fashion

En algunos casos el uso de estos paquetes educativos se encuentra limitado al país de procedencia de la institución o existen restricciones en la utilización de determinados materiales debido a cuestiones legales, lo que supone una importante barrera en el aprovechamiento de estas iniciativas (Ubois, 2006).

\section{Proyectos de colaboración no lucrativos}

Algunas instituciones públicas están desarrollando iniciativas colaborativas para hacer accesible a los ciudadanos parte del patrimonio audiovisual, como Birth - Television
Archive, donde la BBC, la Radio Télévision Belgique Française (RTBF), la alemana Südwestrundfunk (SWR), la austriaca Österreichischer Rundfunk (ORF), y el Nederlands Instituut voor Beeld en Geluid, incluyen un muestra de sus fondos de los primeros cincuenta años de emisión. En una línea similar Videoactive permite el acceso a una amplia selección de programas de televisión e imágenes procedentes entre otros del INA, BBC, ORF, RTBF, DR o TV3. En este proyecto priman los contenidos que conllevan una comparación entre las diferentes culturas europeas (Fernández-Quijada; Fortino, 2009).

http://www.birth-of-tv.org/birth

http://www.videoactive.eu

Actualmente se encuentra en fase de desarrollo el proyecto MED-MEM (Mémories audiovisuelles de la Méditerraneé), subvencionado por la Comisión Europea en respuesta al programa Heritage IV Programme, dirigido por el INA y en el que participan entre otros COPEAM, la televisión argelina $E P T V$, la jordana JRTV, la televisión israelí IBA, la televisión griega ERT o la European Broadcasting Union. Y por supuesto debemos mencionar el proyecto Europeana, que permitirá acceder y explorar diversas colecciones audiovisuales de instituciones como el INA, así como Euscreen en el que participan veintiocho archivos europeos.

http://www.europeana.eu/portal

http://www.euscreen.eu

En el sector de los archivos fílmicos europeos, destaca el proyecto European film treausure que permite acceder a una selección de clips de diversas instituciones, como la Svenska Filminstitutet, el archivo audiovisual de Helsinki, la Cinemateca francesa, el Imperial War Museum o el archivo ruso Gosfilmofond. Y desde hace tan solo unos pocos meses se encuentra ya operativo European film gateway, con más de 400.000 videos, fotografías y pósters del patrimonio fílmico europeo.

http://www.europafilmtreasures.eu

http://www.europeanfilmgateway.eu 


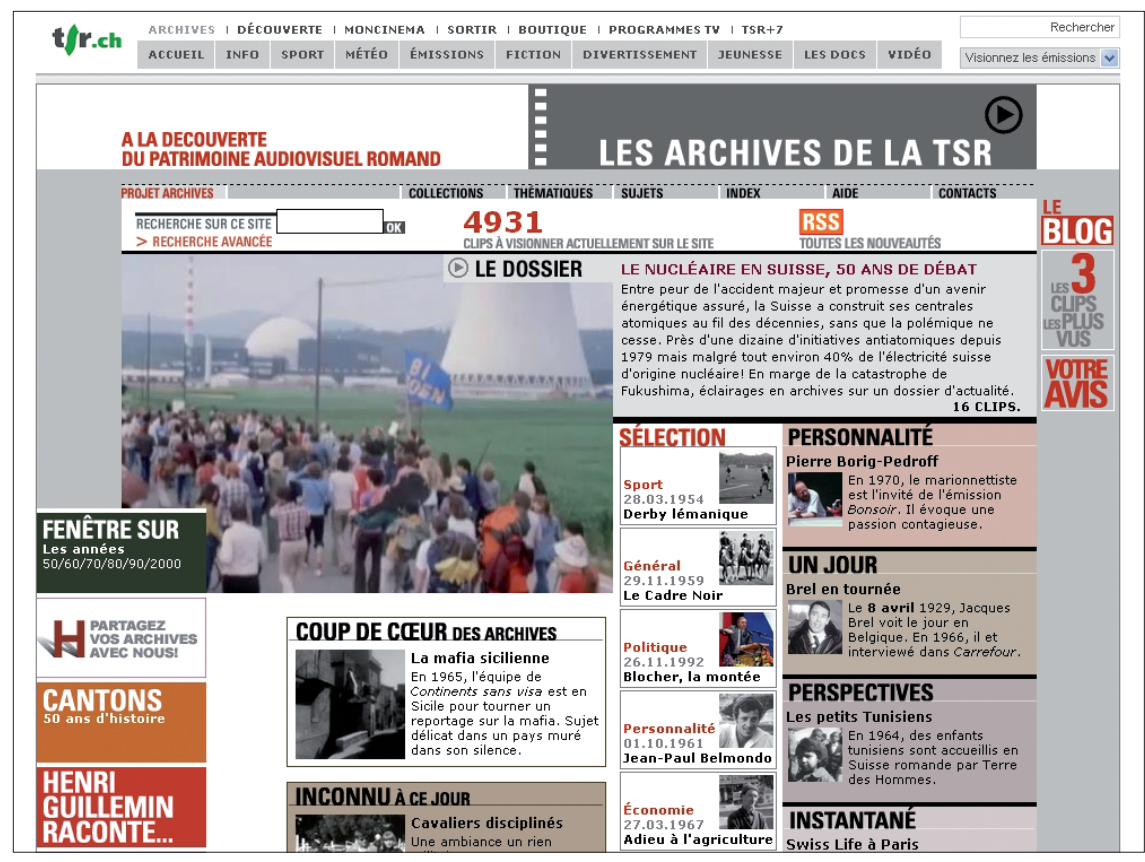

Página del archivo de la TSR

En Reino Unido nos encontramos con la iniciativa Moving history desde cuya web se accede a más de 100 clips procedentes de 15 archivos audiovisuales públicos, como el Imperial War Museum, National Screen and Sound Archive of Wales, el British Film Institute o el Scottish Screen Archive. http://www.movinghistory.ac.uk

\section{Reflexiones y conclusiones}

Tras este recorrido por los servicios de los archivos audiovisuales en internet, se pueden establecer algunas conclusiones.

La puesta en valor de los fondos de los archivos audiovisuales, supone la creación de servicios de valor añadido para diferentes tipos de usuarios, a través de la editorialización y la contextualización de los materiales audiovisuales. Ya no sólo es importante la imagen, sino toda la información y metadatos que la acompañan y la enriquecen.

La digitalización y el acceso a través de internet ha favorecido un acercamiento de los archivos a los usuarios y viceversa. En muchos casos, a éstos les bastará con realizar una búsqueda en la página web del centro y ampliar la misma con búsquedas en otros archivos para localizar similares o diferentes materiales audiovisuales.

La existencia de fondos audiovisuales de libre acceso en la Web favorece el trabajo de los documentalistas en las producciones audiovisuales

La incorporación de fondos audiovisuales de libre acceso en la Web favorece el desarrollo de la labor de los documentalistas en las producciones audiovisuales, ya que desde su puesto de trabajo acceden a numerosos fondos digitalizados.
El acceso libre a fondos audiovisuales posibilita que cualquier usuario pueda ahora navegar y bucear por las imágenes; por ejemplo, directores y guionistas cinematográficos, por lo que los archivos audiovisuales en internet se convierten en fuente de inspiración para el cine.

Las imágenes son más accesibles y se pueden comparar rápidamente las procedentes de diversos fondos. Por ello, una tendencia de futuro puede ser la reducción de tarifas de imágenes para aumentar la competitividad.

El hecho de que los archivos sean más sociales y participativos puede implicar una pérdida de autoridad por parte del propio archivo en el momento en que el usuario puede añadir y enriquecer las imágenes mediante notas y comentarios (Palmer, 2009; Oomen et al., 2010; Yekel; Shaw; Reynolds, 2007). Consideramos que esa debe ser la tendencia: que el archivo conecte con el usuario, que fomente su participación y que se alimente de todas las aportaciones que pueda realizar, previa comprobación de toda esa información.

\section{Bibliografía}

Crymble, Adam. "An analysis of Twitter and Facebook use by the archival community". Archivaria, 2010, n. 70, pp. 125151.

http://www.crymble.ca/adam/cv/publications/CrymbleArchivaria.pdf

De-la-Cuadra-Colmenares, Elena. "British Pathé. Análisis de la página web de un archivo fílmico". Cuadernos de documentación multimedia, 2005, v. 16, pp. 70-77.

http://multidoc.rediris.es/cdm/include/getdoc.php?id= 181\&article...

Emm, Adèle. Researching for television and radio. Londres, Routledge, 2002. ISBN 0415243874

Fernández-Quijada, David; Fortino, Montserrat. "Servicio público de televisión y patrimonio audiovisual: el proyecto VideoActive". El profesional de la información, 2009, septiembre-octubre, v. 18, n. 5, pp. 545-551.

http://eprints.rclis.org/bitstream/10760/15381/1/epi_18_ 5.pdf

http://dx.doi.org/10.3145/epi.2009.sep.09

Gligorov, Riste; Hildebrand, Michiel; Van-Ossenbruggen, Jacco; Schreiber, Guus; Aroyo, Lora. "On the role of usergenerated metadata in audiovisual collections". En: Musen, Mark A.; Corcho, Óscar (eds.). 6th International Conference on Knowledge Capture (K-CAP 2011), June 26-29, 2011, Banff, Alberta, Canada, pp. 145-152.

http://www.cs.vu.nl/ guus/papers/Gligorov11a.pdf

López-de-Quintana, Eugenio. "La explotación comercial de los archivos audiovisuales". Cuadernos de documentación multimedia, 1998, v. 6-7. 
http://www.ucm.es/info/multidoc/multidoc/revista/cuad67/quintana.htm

Nachreiner, Thomas. "The digitization of audiovisual archives. Technological change within the structures of reproduction". En: Maj, Anna; Riha, Daniel (eds.). Digital memories exploring critical issues, 2009. ISBN 9781848880047 http://www.inter-disciplinary.net/wp-content/uploads/ 2009/03/nachreiner_paper.pdf

Oomen, Johan; Belice Baltussen, Lotte; Limonard, Sander; Brinkerink, Maarten; Van-Ees, Annelies; Aroyo, Lora; Vervaart, Just; Afsar, Kamil. "Emerging practices in the cultural domain. Social tagging of audiovisual heritage". En: Proceedings of the websci10: Extending frontiers of society on line. 2010, abril.

http://journal.webscience.org/337/2/websci10_submis sion_23.pdf

Palmer, Joy. "Archives 2.0. If we build it, will they come?". Ariadne, 2009, julio, n. 60.

http://www.ariadne.ac.uk/issue60/palmer/
Rubio-Lacoba, María. “Documentalistas de prensa ¿cuál es vuestro oficio?". El profesional de la información, 2010, noviembre-diciembre, v.19, n.16, pp. 645-651.

http://eprints.rclis.org/bitstream/10760/15121/1/645-651. $p d f$

http://dx.doi.org/10.3145/epi.2010.nov.11

Ubois, Jeff. "Finding Murphy Brown: how accessible are historic television broadcast?". Journal of digital information, 2006, v. 7, n. 2.

http://journals.tdl.org/jodi/article/viewPDFInterstitial/ 172/155

Ubois, Jeff. "New approaches to television archiving". First monday, 2005, marzo, v. 10, n. 3-7.

http://firstmonday.org/htbin/cgiwrap/bin/ojs/index.php/ $\mathrm{fm} /$ article/view/1210/1130

Yekel, Elizabeth; Shaw, Seth; Reynolds, Polly. "Creating the next generation of archival finding aids". D-lib magazine, 2007, mayo-junio, v. 13, n. 5-6.

http://www.dlib.org/dlib/may07/yakel/05yakel.html

http://dx.doi.org/10.1045/may2007-yakel

\section{Próxima aparición}

\section{LIBROS DE BOLSILLO “EL PROFESIONAL DE LA INFORMACIÓN"}

\section{Nueva colección de libros de información y documentación}

Dirigida por Javier Guallar y Tomàs Baiget

\section{Primeros títulos:}

Tecnologías de la web semántica Juan-Antonio Pastor

La revolución del libro electrónico José-Antonio Cordón

Sistemas de información en la empresa

Josep Cobarsí

La información en movimiento Natalia Arroyo

Acceso abierto a la ciencia Ernest Abadal

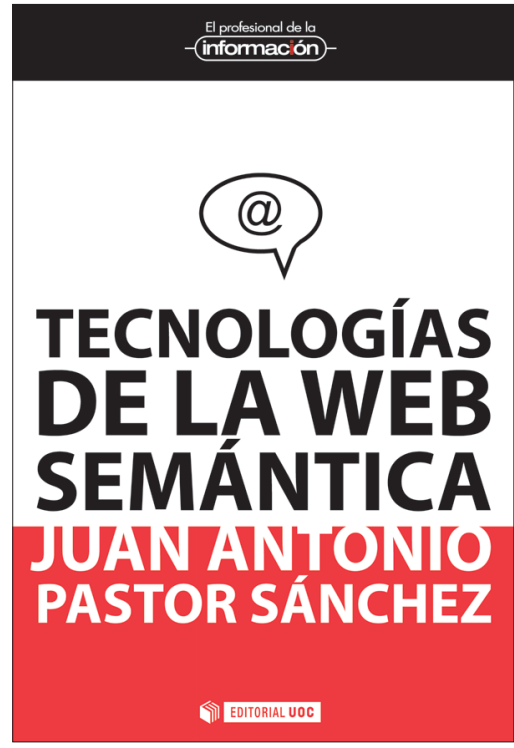

\section{Un proyecto conjunto de}

\section{El profesional de la} información 